\title{
Aerosol microphysical retrievals from precision filter radiometer direct solar radiation measurements and comparison with AERONET
}

\author{
S. Kazadzis ${ }^{1}$, I. Veselovskii ${ }^{2}$, V. Amiridis ${ }^{3}$, J. Gröbner ${ }^{4}$, A. Suvorina ${ }^{2}$, S. Nyeki ${ }^{4}$, E. Gerasopoulos ${ }^{1}$, N. Kouremeti ${ }^{4}$, \\ M. Taylor ${ }^{1}$, A. Tsekeri ${ }^{3}$, and C. Wehrli ${ }^{4}$ \\ ${ }^{1}$ Institute for Environmental Research and Sustainable Development (IERSD), National Observatory of Athens (NOA), \\ Metaxa and Vas Pavlou, Penteli, 15236, Athens, Greece \\ ${ }^{2}$ Physics Instrumentation Center, Moscow, Russia \\ ${ }^{3}$ Institute for Astronomy, Astrophysics, Space Applications and Remote Sensing (IAASARS), \\ National Observatory of Athens (NOA), Metaxa and Vas. Pavlou, Penteli, 15236, Athens, Greece \\ ${ }^{4}$ Physikalisch-Meteorologisches Observatorium Davos, World Radiation Center - PMOD/WRC, Davos, Switzerland
}

Correspondence to: S. Kazadzis (kazadzis@noa.gr)

Received: 4 December 2013 - Published in Atmos. Meas. Tech. Discuss.: 10 January 2014

Revised: 26 May 2014 - Accepted: 28 May 2014 - Published: 4 July 2014

\begin{abstract}
Synchronized sun-photometric measurements from the AERONET-CIMEL (AErosol RObotic NETwork) and GAW-PFR (Global Atmospheric Watch-Precision Filter Radiometer) aerosol networks are used to compare retrievals of the aerosol optical depth (AOD), effective radius, and volume concentration during a high-temporal-resolution measurement campaign at the Athens site in the Mediterranean Basin from 14 to 22 July 2009. During this period, direct-sun AOD retrievals from both instruments exhibited small differences in the range 0.01-0.02. The AODs measured with CIMEL and PFR instruments were inverted to retrieve particle microphysical properties using the linear estimation (LE) technique. For low aerosol loads (AOD $<0.2$ ), measurements of the effective radius by the PFR were found to be $-20 \%$ to $+30 \%$ different from CIMEL values for both direct-sun data and inversion data. At higher loads $(A O D>0.4)$, measurements of the effective radius by the PFR are consistently $20 \%$ lower than CIMEL for both directsun and inversion data. Volume concentrations at low aerosol loads from the PFR are up to $80 \%$ higher than the CIMEL for direct-sun data but are up to $20 \%$ lower when derived from inversion data under these same conditions. At higher loads, the percentage difference in volume concentrations from the PFR and CIMEL is systematically negative, with inversion data predicting differences $30 \%$ lower than those obtained from direct-sun data.
\end{abstract}

An assessment of the effect of errors in the AOD retrieval on the estimation of PFR bulk parameters was performed and demonstrates that it is possible to estimate the particle volume concentration and effective radius with an uncertainty $<65 \%$ when $\mathrm{AOD}<0.2$ and when input errors are as high as $10 \%$.

\section{Highlights}

- A comparison of high-temporal-resolution synchronous CIMEL and PFR (Precision Filter Radiometer) directsun aerosol optical depth (AOD) measurements.

- Calculation of bulk aerosol microphysics parameters using a linear estimation (LE) inversion technique.

- A comparison of retrieved aerosol volume concentrations and effective radii from CIMEL and PFR inversions.

- An analysis of the sensitivity of PFR retrievals to random errors on the optical input data. 


\section{Introduction}

The quantification of aerosol properties and their spatial and temporal variability is crucial in order to define their forcing effect on climate. Since this has not yet been done effectively, the uncertainty associated with the impact of aerosols is very large, especially with respect to global warming resulting from the forcing effect of greenhouse gases (Hansen et al., 2005; IPCC, 2007). More specifically, aerosols exert a direct forcing on climate by reflecting or absorbing incoming sunlight, and an indirect forcing on climate by altering cloud properties and precipitation. However, it is not possible to quantify both forcing effects to the required accuracy if the microphysical properties of aerosols (i.e. size, shape, and chemical composition) and their interaction with clouds are not described adequately (Mishchenko et al., 2007).

Although the spatial and temporal resolution required for global studies of the effect of aerosols on climate can only be effectively achieved through satellite observations (Hansen et al., 1997), ground-based observations play an important role in aerosol monitoring and for the validation of satellite retrievals. One of the most prominent ground-based networks is the AErosol RObotic NETwork (AERONET). AERONET is a network of CIMEL sun photometers which measure atmospheric aerosol properties (Holben et al., 1998).

Numerous studies have been published using different aerosol related parameters derived from AERONET in the past two decades, establishing it as a globally recognized source of information about particle properties. Measurements of sun and sky radiances at a number of fixed wavelengths within the visible and near-infrared spectrum are performed, and advanced retrieval algorithms for retrieving microphysical aerosol properties have been developed (Dubovik and King, 2000) and assessed (Dubovik et al., 2000) in the framework of AERONET. AERONET products for dust aerosol worldwide are presented (along with other aerosol types) in the AERONET climatology study of Dubovik et al. (2002). Furthermore, the study of Dubovik et al. (2006) demonstrates how the non-spherical model included in the AERONET inversion algorithm accounts for the non-sphericity of dust particles. The AERONET dust product is expected to be further enhanced in the new GARRLiC algorithm, which combines sun-photometric measurements with lidar measurements (Lopatin et al., 2013). Validation studies comparing column-averaged volume size distributions obtained from sun-photometer measurements with direct in situ measurements from aircraft as well as at the surface (Haywood et al., 2011; Toledano et al., 2011; Gerasopoulos et al., 2007) are key to helping systematically validate microphysical inversion products (IPCC AR5, 2013, Chapter 7, p. 603) from AERONET.

Another ground-based network, the Global Atmospheric Watch (GAW) network operated since 1999 by the World Optical Depth Research and Calibration Center (WORCC), is based at the World Radiation Center of the World
Meteorological Organization (WMO) at Davos, Switzerland. Under the auspices of the WORCC, 12 existing GAW stations were chosen for the deployment and operation of a corresponding number of 12 PFRs (Wehrli, 2005). The GAWPFR network provides quality assured, high-quality spectral AOD data with nearly continuous temporal coverage. Due to its excellent stability (degradation significantly less than $1 \%$ year $^{-1}$ ), recalibrations are done bi-annually (or even less frequently) to minimize data gaps. In contrast to AERONET where station gaps due to recalibrations can be 6 months every 18 months (66\% data availability or less), the comparable value of GAW-PFR stations is of the order of $90 \%$ or more. The main objective of the GAW-PFR network is to provide homogeneous data on decadal timescales with the highest possible accuracy. PFR instruments are installed at GAW stations to monitor background aerosol concentrations so as to not be affected by local changes (urbanization, etc). Finally, the traceability of GAW-PFR leads directly to the World Optical Depth Research and Calibration Center, which was selected by the WMO to act as world reference centre for AOD measurements to which all other networks should be traceable, including AERONET.

Compared to the AERONET-CIMEL sun- and skyscanning photometer, the GAW-PFR as a classic sun photometer provides more limited optical data (PFR provides only four AODs while CIMEL provides seven), and the retrieval of complete particle microphysical properties from this data set is correspondingly more limited. For many applications though, it is sufficient to retrieve bulk aerosol properties such as the volume concentration $\left(V_{\mathrm{c}}\right)$ and the effective radius $\left(R_{\text {eff }}\right)$ of the particle size distribution. These parameters are appropriate for use in radiation studies (instead of for example the number concentration and the mean radius) since they are more sensitive to the radiative properties of the particles (Mischenko et al., 2006; Bohren and Huffman, 1983).

An assessment of AERONET product accuracy is provided in Dubovik et al. (2000), where the inversion is tested on synthetic data considering different aerosol types (watersoluble aerosol, biomass burning, and dust) and taking into account also random measurement errors and systematic errors arising from miscalibration, azimuth angle pointing, and surface reflectance. Therein, the accuracy of the retrieved volume size distribution $(\mathrm{d} V / \mathrm{d} \ln r)$ for dust is estimated to be $35 \%$ for $0.1 \mu \mathrm{m}<r<7 \mu \mathrm{m}$ and $35-100 \%$ for $r<0.1 \mu \mathrm{m}$ and $r>7 \mu \mathrm{m}$. Note that this uncertainty analysis was performed before non-spherical particle modelling was included in the AERONET inversion scheme. Dubovik et al. (2006) show that the new inversion scheme, taking into account the non-spherical shape of the particles, provides better fits to sky radiances and AODs used for the retrieval of dust aerosol in terms of measurement accuracy, whereas the spherical model results in much greater fitting errors. Validation studies of the AERONET volume size distribution for dust aerosol using independent data show varying 
levels of agreement. For example, in Toledano et al. (2011) the comparison with in situ airborne data during the Saharan Mineral Dust Experiment (SAMUM) SAMUM-II campaign showed good agreement for the shape of the size distribution, although the effective radius of the coarse mode from AERONET was smaller than that measured with in situ onboard instruments. Müller et al. (2010) report even more significant differences for both the fine and coarse mode of dust particles, compared with aircraft and ground-based in situ measurements performed during the SAMUM-I campaign.

\section{Instrumentation and methods}

In order to harmonize the AERONET-CIMEL and GAWPFR networks, calibration and intercomparison activities have been initiated. We report on one such activity that was coordinated in Athens, Greece, during the period 1422 July 2009. The LE technique (see Sect. 2.2 for details) was applied to data sets from both networks, and the $V_{\mathrm{c}}$ and $R_{\text {eff }}$ of the size distribution were estimated, along with an assessment of the effect of instrumental errors on the uncertainty on the retrieval. Furthermore, the results are compared with their AERONET inversion product counterparts in order to assess the capabilities of the LE technique.

\subsection{Aerosol sun-photometric measurements}

A PFR travelling standard from the WORCC was located at the aerosol monitoring station of the Institute for Astronomy, Astrophysics, Space Applications and Remote Sensing (IAASARS) at the National Observatory of Athens (NOA), $191 \mathrm{~m}$ a.s.l. The station is located in a suburban area, $3 \mathrm{~km}$ from the centre of Athens where IAASARS/NOA has also been operating a CIMEL sun photometer as part of AERONET since 2008.

Measurements by the PFR travelling standard were taken at 1 min intervals and were evaluated according to GAW-PFR Level 3 data standards (see below). According to these standards, data are (i) cloud-screened, (ii) manually inspected, and (iii) pre-calibrated without a post-field campaign calibration (further details can be found on the WORCC website at www.pmodwrc.ch/worcc/ under the menu "AOD QC/Calibration"). Measurements by the CIMEL sun photometer were run according to the accepted AERONET protocol whereby the measurement frequency depends on the optical air mass and time of day. In practice, AOD measurements are available every 10-11 min during low sun elevations and are available in near-real time from the AERONET website (http://aeronet.gsfc.nasa.gov/). Level 2 AOD data obtained from the AERONET Version 2 direct-sun algorithm (SDA) were collected. AERONET Level 2 data are (i) pre- and post-field calibrated, (ii) automatically cloudscreened, and (iii) manually inspected (further details concerning AERONET data processing procedures for AOD
Table 1. PFR and CIMEL measuring characteristics.

\begin{tabular}{lll}
\hline & CIMEL & PFR \\
\hline Central wavelengths & $1639.8, \quad 1017.7, \quad 870$, & $861.6, \quad 500.5, \quad 411.4$, \\
& $672.7, \quad 500.1, \quad 438.5$, & and 367.6nm \\
& 379.7, and $339 \mathrm{~nm}$ & \\
\hline FWHM & $\begin{array}{l}2 \mathrm{~nm} \text { for } 340 \mathrm{~nm} \\
4 \mathrm{~nm} \text { for } 380 \mathrm{~nm}\end{array}$ & $5.4,5.0,4.5$, and $3.8 \mathrm{~nm}$ \\
& $\begin{array}{l}10 \mathrm{~nm} \text { for the other } \\
\text { wavelengths }\end{array}$ \\
\hline Field of view & $1.2^{\circ}$ & \\
\hline
\end{tabular}

retrievals can be found at http://aeronet.gsfc.nasa.gov/new web/data_description_AOD_V2.html and those related to inversion products at http://aeronet.gsfc.nasa.gov/new_web/ Documents/Inversion_products_V2.pdf). In Table 1 there is a description of the main measurements' basics (measuring wavelengths, full widths at half maximum for every channel, and field of view) of each one of the CIMEL and PFR instruments.

\subsection{Microphysical retrievals}

The AERONET retrieval provides a large number of aerosol microphysical and optical properties. In particular, the volume size distribution $\mathrm{d} V / \mathrm{d} \ln r$ is retrieved in $22 \operatorname{loga}-$ rithmically equidistant radial $(r)$ bins in the size range $0.05 \mu \mathrm{m} \leq r \leq 15 \mu \mathrm{m}$. The real $\left(m_{\mathrm{R}}\right)$ and imaginary part $\left(m_{\mathrm{I}}\right)$ of the complex refractive index $(m)$ (where $1.33 \leq m_{\mathrm{R}} \leq 1.6$ and $0.0005 \leq m_{\mathrm{I}} \leq 0.5$ ) are retrieved for wavelengths corresponding to sky radiance measurements. In addition, the retrieval provides the following standard parameters for the total and the fine and coarse aerosol modes of the size distribution: $V_{\mathrm{c}}\left(\mu \mathrm{m}^{3} / \mu \mathrm{m}^{2}\right), R_{\mathrm{eff}}(\mu \mathrm{m})$, and the volume median radius (not considered here).

However, the number of CIMEL sky radiance scans is normally limited to typically one scan per hour. In addition, the accuracy of the particle property retrieval is lower at high solar zenith angles (SZAs) and low AOD $<0.4$ (Dubovik and King, 2000). As a result of these constraints, a significant proportion of the AERONET measurements are excluded from the Level 2 product. However, direct-sun measurements are performed at higher temporal resolution (typically every $10 \mathrm{~min}$ ), and our aim here is to also assess their utility in deriving bulk measures of aerosol microphysics.

The idea of estimating particle parameters from radiometric measurements by inverting AODs only is not new, and was considered for example by King et al. (1978), but provision of such estimates from PFR measurements is more challenging because only four AODs are available and the problem is strongly underdetermined. Similar problems have been found to occur in the retrieval of particle parameters from multi-wavelength Raman measurements (Müller et al., 1999; Veselovskii et al., 2002, 2012), and it is of interest 
see how the experience accumulated in contemporary lidar studies can be applied to better constrain the inversion of solar radiometer measurements (see below). For the retrieval considered here, the inversion scheme based on expansion of the particle size distribution in terms of measurement kernels was chosen (Twomey, 1977; Thomason and Osborn, 1992; Donovan and Carswell, 1997; Veselovskii et al., 2012). In this framework, the bulk particle parameters $V_{\mathrm{c}}$ and $R_{\text {eff }}$ are estimated from a linear combination of input optical data, and we will refer to this method as the linear estimation technique.

Our positive experience of applying the LE technique to lidar measurements has demonstrated that it is fast and stable (Veselovskii et al., 2012, 2013), and therefore is a good candidate for inversion of AOD data. Having said this, there is an essential difference between lidar and solar radiometer measurements. Multi-wavelength Raman lidar provides backscattering and extinction coefficients at multiple wavelengths, while solar radiometers provide only AODs. Furthermore, for lidar, backscattering measurement kernels are shifted to larger radii in comparison to extinction measurement kernels (Donovan and Carswell, 1997); thus retrieval of the coarse mode should be more complicated when AODs alone are used. On the other hand, for AOD measurements a lower uncertainty of $5 \%$ is often available in contrast to calculation of particle extinction and backscattering coefficients from lidar measurements where achieving an uncertainty below $10 \%$ is problematic. Keeping in mind that solution of inverse problem is sensitive to the errors in the input data, the superior accuracy of AOD measurements could provide an advantage. One of the goals of the current work was to test whether or not the LE algorithm is capable of providing a useful estimation of bulk particle parameters from AOD measurements alone.

A detailed description of the LE technique is presented in Veselovskii et al. (2012), and here we provide the main steps of the inversion procedure relevant to an understanding of how the size distribution is obtained from available inputs. More specifically, the input vector $\boldsymbol{g}$ contains the input optical data (the spectrum of AODs) and is related to the volume size distribution $\boldsymbol{v}$ as follows:

$\mathbf{K} v=g$

where $\mathbf{K}$ is a matrix containing the discretized volume kernels (as rows). The volume size distribution is then expanded in terms of the measurement kernels. Any bulk particle property $\boldsymbol{p}$ (e.g. $V_{\mathrm{c}}$ or $\left.R_{\text {eff }}\right)$ can be estimated from Eq. (1) as follows:

$\boldsymbol{p}=\mathbf{P} \boldsymbol{v}=\mathbf{P} \mathbf{K}^{T}\left(\mathbf{K K}^{T}\right)^{-1} \boldsymbol{g}$,

where $P_{i k}$ is a matrix containing the weight coefficients of different integral properties occurring in each row $i$. For example, for volume $(i=1)$, surface $(i=2)$, and number con- centrations $(i=3), P_{1 k}=1, P_{2 k}=\frac{3}{r_{k}}$, and $P_{3 k}=\frac{3}{4 \pi r_{k}^{3}}$, respectively. It should be mentioned that when retrieving $\boldsymbol{p}$, we consider only the projection of $\boldsymbol{p}$ on the measured set $\boldsymbol{g}$ and ignore the residual $\boldsymbol{p}_{\perp}$ that cannot be measured directly with the available set of observations $\boldsymbol{g}$ (the so-called "null space"). The corresponding uncertainty can be estimated via numerical simulating typical particle size distributions (PSDs). As will be shown in Sect. 3.3, the uncertainty of the retrieval of $V_{\mathrm{c}}$ related to the existence of the null space may be as high as $10 \%$ for PSDs where the fine mode is dominant but can increase to $50 \%$ when the coarse mode dominates.

The inverse problem, in this formulation, is underdetermined (i.e. the set of input optical data measurements is limited and is generally not sufficient to obtain a unique solution). Moreover, the solution also depends upon a chosen inversion interval for the particle radius $\left[r_{\min }, r_{\max }\right]$ as well as the refractive index $m$, which are both unknowns. In order to address this, in our approach, we perform the retrieval for a set of predetermined inversion intervals and values of $m$. To be more specific, we consider a set of inversion intervals in the range $0.075-10 \mu \mathrm{m}$, and a set of refractive indices whose real part $m_{\mathrm{R}}$ is in the range $1.35-1.65$ and whose imaginary part $m_{\mathrm{I}}$ is in the range $0-0.02$. Thus, instead of a single solution, we obtain a family of solutions, and the selection is performed based on the resulting discrepancy as described in Veselovskii et al. (2012). The discrepancy $\rho$ is defined as the difference between the measured data $g_{p}$ and the calculated data $\tilde{g}_{p}$ derived from the inversion. In the LE technique we obtain $N$ estimates of $\tilde{g}_{p}$, using, for each one, $N-1$ measurements from the measured data $g_{p}$ as suggested in De Graaf et al. (2013). The discrepancy $\rho$ is then calculated using the expression

$\rho=\sqrt{\frac{\sum_{p}^{N}\left(g_{p}-\tilde{g}_{p}(m)\right)^{2}}{N} .}$

Solutions are then sorted in descending order in accordance with their discrepancy, and the bottom $1 \%$ near the discrepancy minimum are averaged to produce the final solution.

The maximum particle radius considered in our retrieval is $10 \mu \mathrm{m}$, while in AERONET's operational algorithm the inversion interval extends out to $15 \mu \mathrm{m}$. The smaller value of $r_{\max }$ in our LE retrieval is due to the low sensitivity of AOD measurement kernels to larger particles (further increasing $r_{\max }$ only increases the uncertainty of retrieval). Higher values of $r_{\max }$ in the AERONET algorithm are possible due to the availability also of the angular spectrum of sky radiance. As a result, we expect an underestimation of the coarse mode when only AODs are considered. It should be mentioned also that the AOD, in contrast to the aerosol backscattering coefficient, is not very sensitive to the refractive index $m$, and hence errors arising from a possibly incorrect choice of $m_{\mathrm{R}}$ 

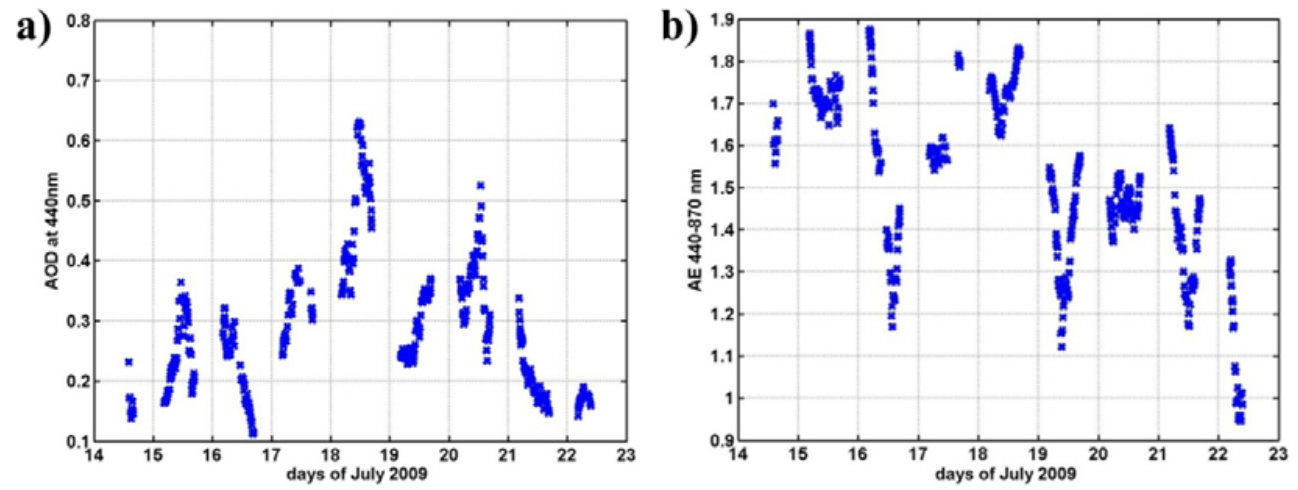

Figure 1. (a) AOD at $440 \mathrm{~nm}$ and (b) the AE at 440-870 $\mathrm{nm}$ as monitored over Athens by the GAW-PFR instrument.

and $m_{\mathrm{I}}$ are not expected to be significant. Further discussion of the uncertainties associated with the retrieval is provided in section 3.3.

\section{Results and discussion}

\subsection{Aerosol variability during the experiment}

The AOD at $440 \mathrm{~nm}$ and the Ångstrom exponent (AE) at 412-870 nm from GAW-PFR measurements during the study period are presented in Fig. 1. Both the AOD and the AE show high variability. This is because the Mediterranean Basin is under the influence of a dust event. In particular, on 14 July, a dust tongue is situated over the western part of the basin (as revealed by simulations from the Barcelona $\mathrm{Su}-$ percomputing Center DREAM model not shown here). On the days that follow, the dust cloud extended eastwards and influenced measurements at the Athens site during the period 16-19 July, with remnants still observable on 20 July. During the period 16-18 July, another dust tongue originating from the Arabian Peninsula converged on the area and resulted in intermittent breaks between dusty and clear conditions.

According to the study of this region by Gerasopoulos et al. (2011), in the summer period, the build-up of particles due to intense photochemical processes favored by high temperature and insolation contributes to elevated AOD levels in a way that reflects the geographical spread of particle precursor sources and transport processes. In comparison, the average (2006-2008) summer AOD (at $500 \mathrm{~nm}$ ) is $0.22(0.27$ at $440 \mathrm{~nm}$ ), and this value is exceeded during four consecutive days during the measurement period (17-20 July) either due to the presence of dust (e.g. on 19 July the $\mathrm{AE} \leq 1.1$ ) or due to the presence of a mixture of dust with local or transported pollution as can be seen in Fig. 1. The presence of coarse-mode aerosol is evident also on 16, 21, and 22 July, but can be seen to originate from lower AOD levels. The average daily temperature during this period ranged from 25 to $30^{\circ} \mathrm{C}$, with the highest temperatures observed between 18 and 21 July.
In order to assess the contribution of fine- and coarse-mode particles on aerosol loads, the aerosol size distribution (spanning 22 logarithmic radial bins in the interval $0.05-15 \mu \mathrm{m}$ ) obtained from the AERONET Level 2 Version 2 inversion product is shown in Fig. 2.

During the whole experimental period, a bimodal distribution of aerosols is observed. The fine mode presents the highest volume concentrations $V$ with peaks on 15 July and from 18-20 July centred at $r=0.15 \mu \mathrm{m}$. The coarse mode is centred at $r=5.1 \mu \mathrm{m}$ but exhibits a much broader distribution of particle volumes spanning radial bins from $r=1.3$ to $8.7 \mu \mathrm{m}$. This size range is typical for dust aerosols in the Mediterranean Basin (Gerasopoulos et al., 2007). On the days where the dust influence is most pronounced, the distribution of coarse particles appears to be skewed towards smaller radius particles. In contrast to local dust re-suspension, this might reflect scavenging of coarser dust particles as they migrate from the source over the study area (Fotiadi et al., 2006). However, it is also not possible to exclude the possible presence of sea salt particles in the region from an activated sea breeze cell over Athens during the experimental period.

Overall, the location of peaks in the volume size distribution in Fig. 2, in conjunction with AOD and AE measurements from GAW-PFR in Fig. 1, suggests that a mixture of local pollution and transported dust particles is dominant during the study period, and that fine-mode particles are the major factor controlling the observation of peaks in the AOD.

\subsection{A comparison of AERONET-CIMEL- and GAW-PFR-retrieved aerosol properties}

\subsubsection{Aerosol optical depth, AOD}

The total measurement period at the Athens AERONET station was 8 days, of which only 1 day was completely cloudy/rainy. Coincident AOD measurements from the two instruments which occurred within \pm 30 s were used for the analysis. The comparison of individual channels was constrained to wavelength differences smaller than $5 \mathrm{~nm}$ of the central wavelength. This condition limits the comparison 


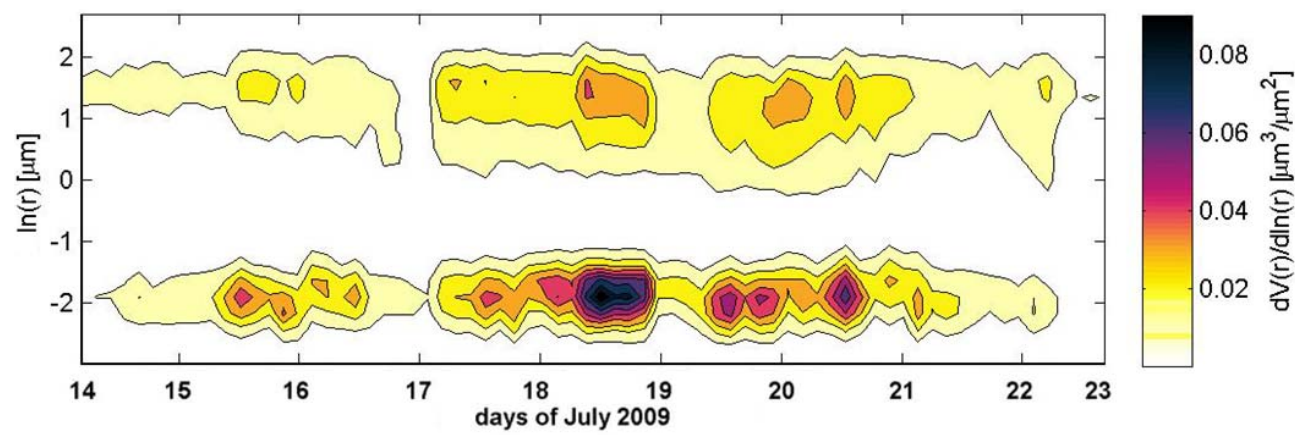

Figure 2. Aerosol size distribution provided by the AERONET Level 2 Version 2 inversion.

between the CIMEL and PFR instruments to two wavelengths at 500 and $865 \mathrm{~nm}$. A total of 471 coincident and cloud-free data points at $500 \mathrm{~nm}$ were collected. Although both AERONET-CIMEL and GAW-PFR instruments use a so-called "triplet" algorithm for cloud screening, GAW-PFR does not currently implement the same criteria as AERONET (Smirnov et al., 2000). For instance, outliers may be encountered as a result of incorrect flagging by the PFR's cloudscreening algorithm. For this reason, further quality control was performed manually, leading to a final data set containing 468 pairs.

Summary statistics calculated for the coincident AOD data showed that the mean AOD difference at 500 and $865 \mathrm{~nm}$ was low ( -0.012 and 0.004 , respectively). Small differences were also apparent in root-mean-square (RMS) values, which were found to be below 0.015 (well within the uncertainty of the AERONET-CIMEL and GAW-PFR field measurements). Further statistics applied to coincident AE measurements showed a reasonable agreement between CIMEL and PFR mean values, calculated to be 1.44 and 1.52 , respectively. When comparing coincident values it should be noted that the AE may depend on the number of wavelength channels used and also on the wavelengths themselves. Both CIMEL and PFR use four wavelengths but slightly different wavelength ranges: 440 to $870 \mathrm{~nm}$ and 368 to $862 \mathrm{~nm}$, respectively. More detail on AOD differences is presented in Fig. 3.

The scatter varies from -0.035 to 0.01 for $500 \mathrm{~nm}$ and -0.01 to 0.01 for $865 \mathrm{~nm}$, with the variation on any particular day being between 0.01 and 0.02 (similar to the quoted AOD uncertainty of 0.015 for both instruments). The offset bias at Athens-NOA is -0.01 and -0.001 at $500 \mathrm{~nm}$ and $865 \mathrm{~nm}$, respectively. At both wavelengths, the Pearson product-moment correlation coefficients are very high (>0.99) and the calculated slopes are 0.99 and 1.04 at 500 and $865 \mathrm{~nm}$, respectively.

The quality of AOD data from the inter-comparison can be gauged by applying the WMO criteria discussed in WMO GAW report number 162 (WMO, 2005). According to these criteria, the ability to trace the calibration to a primary reference ("traceability") is not currently possible based on physical measurement systems. The WMO report states that the initial form of traceability should be based on difference criteria such that an inter-comparison or co-location traceability is established if the AOD difference between networks is within specified limits. In the first instance, the definition of these limits depends on the method of measurement used. For finite field-of-view instruments such as the PFR and CIMEL, the limit ("U95") is defined as follows for air mass $M$ :

$\mathrm{U} 95< \pm(0.005+0.010 / M)$.

The first term accounts for instrumental and algorithmic uncertainties while the second term represents the uncertainty in the exo-atmospheric calibration. The latter corresponds to a requirement for the relative uncertainty in the calibration to be $<1 \%$. Figure 4 illustrates the AOD differences as a function of air mass. At $500 \mathrm{~nm}$, almost half of the data fall outside the WMO limits. In contrast, the $865 \mathrm{~nm}$ channel was traceable, with almost $99 \%$ of the data points fulfilling the current GAW criterion.

It is important to note that a lower AOD limit exists beyond which the AOD difference is difficult to minimize. An AOD inter-comparison study conducted by McArthur et al. (2003) compared a network of PFR and CIMEL sun photometers against other AOD instruments. The study demonstrated that only a marginal improvement in AOD uncertainty at the 0.005 level is obtainable and requires further advances in the following areas: (i) solar pointing; (ii) better determination of Rayleigh reflectance, ozone, and other species' contributions to optical depth; as well as (iii) better instrument characterization (including calibration).

\subsubsection{Effective radius, $\boldsymbol{R}_{\text {eff }}$}

The AOD data sets from both PFR and CIMEL were used as inputs in the LE method to calculate the $V_{\mathrm{c}}$ and $R_{\mathrm{eff}}$ of the particle size distribution. We performed a comparison of the results in order to assess possible differences. In addition, a third data set, the AERONET sky radiance inversion product (considered as a quality standard), was also used for comparison of the results from the PFR and CIMEL LE retrievals. 

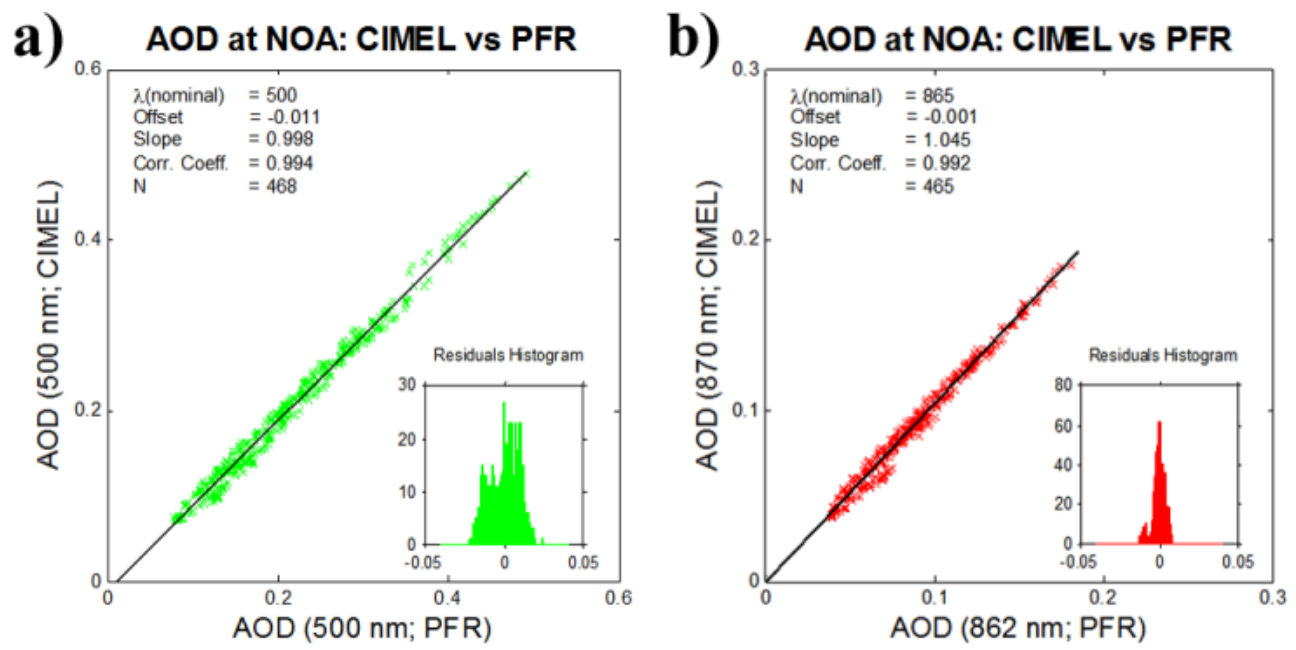

Figure 3. Comparison of direct-sun AODs from CIMEL and PFR at (a) $500 \mathrm{~nm}$ and (b) $865 \mathrm{~nm}$ for the whole measurement period. The plots' insets present the histogram of residual values after the regression analysis.
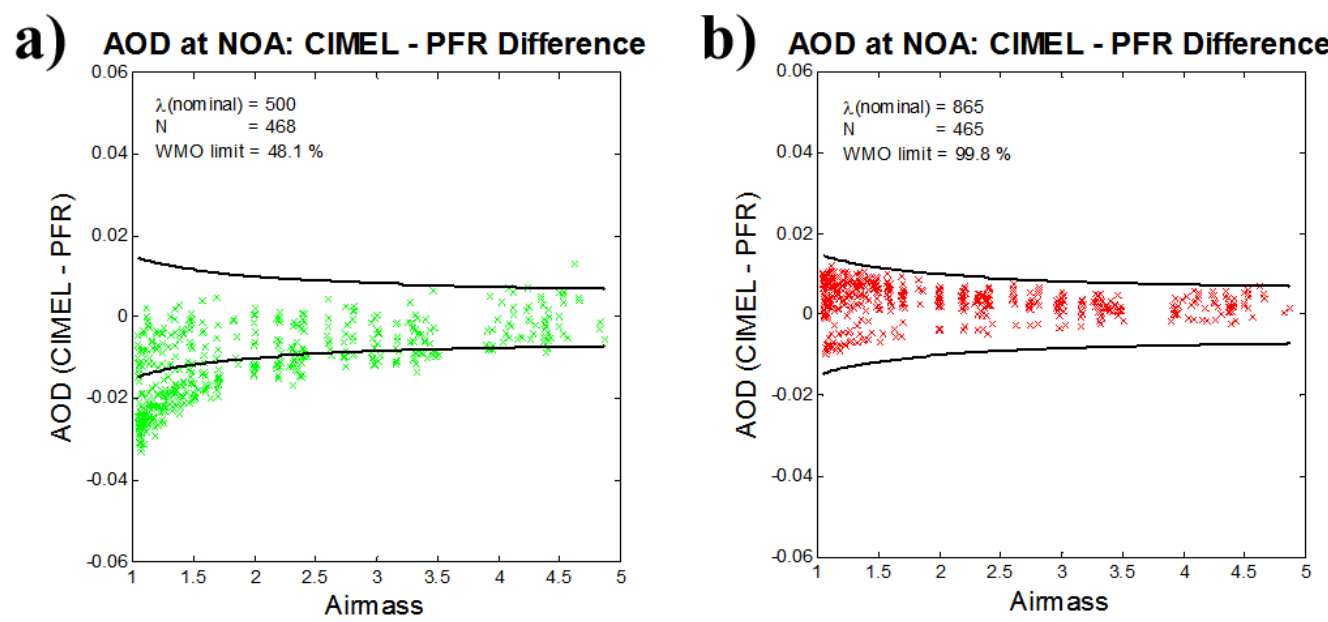

Figure 4. AOD difference (CIMEL-PFR) versus air mass at NOA illustrating the WMO criteria for traceability (solid line) at (a) $500 \mathrm{~nm}$ (green) and (b) $865 \mathrm{~nm}$ (red).

The three different methods used in our analysis are therefore

i. LE method with AOD data from the PFR (termed PFRLE),

ii. LE method with AOD data from the CIMEL (termed AERONET-LE),

iii. AERONET Version 2 inversion products (termed AERONET Inv) (Level 2 when available and Level 1.5 otherwise).

An example for the LE retrievals is shown in Fig. 5, where the expected anti-correlation between $R_{\text {eff }}$ and $\mathrm{AE}$ is observed.
Time series of the $R_{\text {eff }}$ retrieved by the above three methods are presented in Fig. 6. A generally good agreement between the PFR-LE- and AERONET-LE-derived values of $R_{\text {eff }}$ is found (both in terms of absolute values and also in terms of the temporal structure). On days having prominent bimodal distributions (see Fig. 2, 17-20 July) the PFR-LE method seems to slightly underestimate with respect to values derived from the AERONET-LE method. The AERONET inversion code-derived values ("AERONET Inv") of $R_{\text {eff }}$ also show a reasonable agreement with respect to the overall baseline trend given the restrictions of the inversion. Moreover, at high SZAs, it can be seen that the inversion code gives higher $R_{\text {eff }}$ values than the AERONETLE-calculated one. 


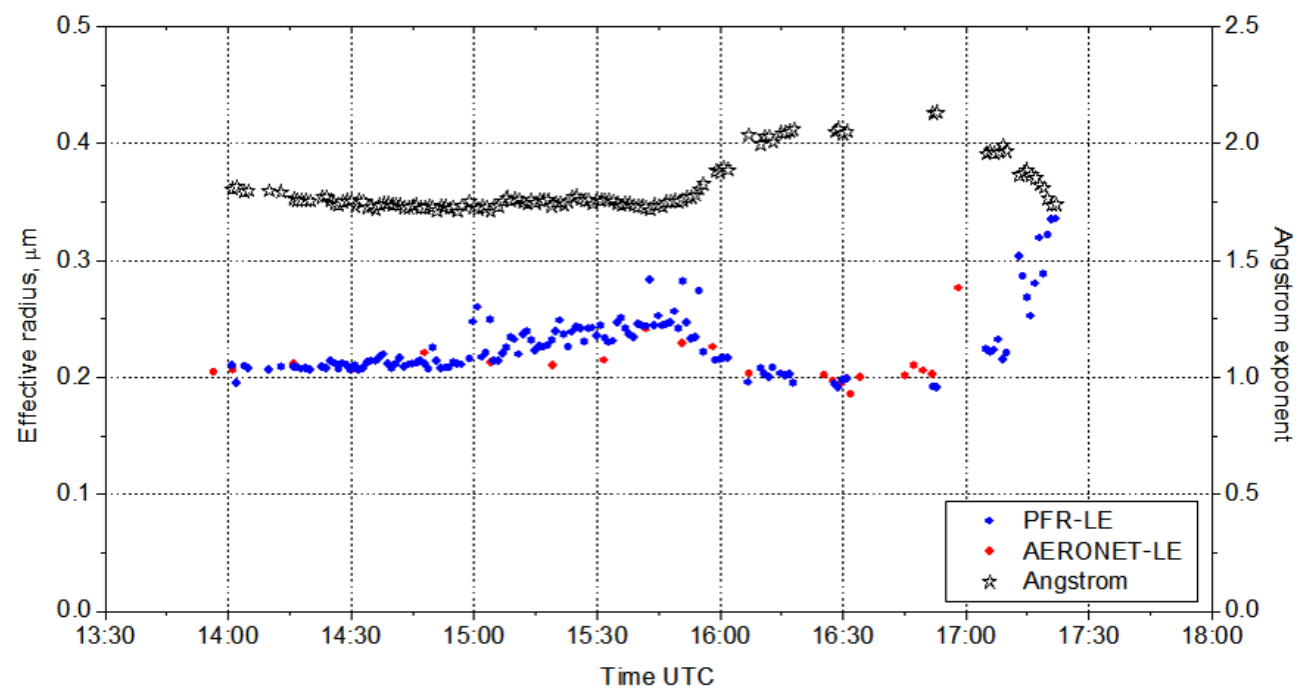

Figure 5. Retrievals of the effective radius for the 14 July calculated from PFR (blue) and CIMEL AERONET (red) direct-sun data using the LE method. Also shown is the CIMEL AERONET Ångstrom exponent (black stars).

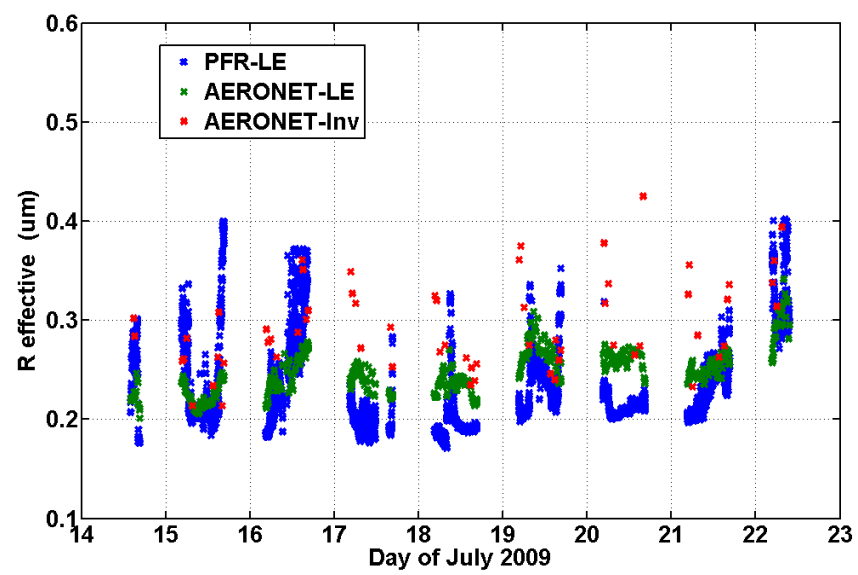

Figure 6. Time series of the effective radius during the measurement period calculated by the PFR (blue $=1$ min resolution) and CIMEL AERONET (green) using the LE method. Also shown is the value obtained from the AERONET Level 2 Version 2 inversion algorithm (red, 8 times per day).

In order to investigate possible sources of discrepancy between the different techniques, the difference between the PFR-LE- and AERONET-LE-derived $R_{\text {eff }}$ values is plotted versus the SZA and the AOD. For both direct-sun measurements and the inversion data, the percentage difference shows a general increase when the SZA $\approx 65-70^{\circ}$ (Fig. 7a). From a fairly constant absolute difference in the range 0 to $-20 \%(-7 \pm 14 \%$ mean and standard deviation) scatter in the direct-sun data increases to as much as $60 \%$ when the $\mathrm{SZA}>70^{\circ}$. A similar pattern is revealed with respect to the AERONET inversion data where the respective mean is $-15 \pm 23 \%$ ( or $-15 \pm 11 \%$ for SZA $<70^{\circ}$ ). The same differences are then plotted as a function of AOD (Fig. 7b).
For low aerosol loads where AOD $<0.2$, the percentage difference between the $R_{\text {eff }}$ obtained from the PFR and CIMEL is mostly positive, reaching a maximum of $\approx 60 \%$ for both direct-sun and inversion data. For higher AOD loads, two distinct regions are discernable. In the range $0.2 \leq \mathrm{AOD} \leq 0.4$, the percentage difference between the PFR and the CIMEL shows a significant spread and is mostly negative for both direct-sun measurements $(0$ to $-0 \%)$ and inversion data. The PFR retrieval predicts lower values of $R_{\text {eff }}$ compared to the CIMEL of the order of 10 and $20 \%$ for the LE and inversion methods, respectively. At moderate to high loads (AOD > 0.4), the effect of PFR predicting lower $R_{\text {eff }}$ values continues, but the percentage difference converges on a narrow band centred at $-20 \%$.

\subsubsection{Volume concentration, $V_{\mathrm{c}}$}

$V_{\mathrm{c}}$ was also retrieved using the above three methods and the time series are shown in Fig. 8.

The agreement between the $V_{\mathrm{c}}$ retrieved from the PFRLE and the AERONET-LE methods is quite good (both in terms of variability and in terms of absolute values). The AERONET inversion also echoes well the timing of the peaks, but is systematically much higher. This underestimation of particle volume in the LE retrieval is due to the presence of a mixture of fine and coarse particles. As mentioned in Sect. 2.2, the measurement AOD kernels are less sensitive to coarse-mode particles and result in a volume underestimation (this will be shown in Sect. 3.3).

Investigating the differences for the three different approaches as a function of AERONET AOD at $440 \mathrm{~nm}$, Fig. 9b shows that the difference between the LE method when PFR and CIMEL measurements of $V_{\mathrm{c}}$ are considered lies among maximum values around -0.01 to $0.02(-5 \%$ and $40 \%)$ at 

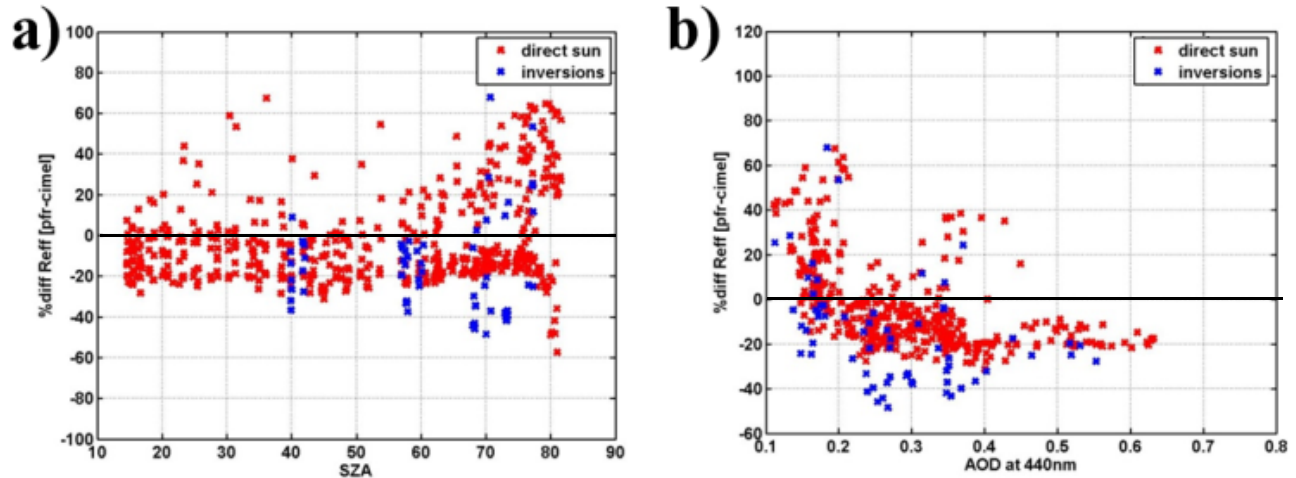

Figure 7. (a) Percentage difference (PFR-CIMEL) of $R_{\text {eff }}$ calculated from direct-sun data using the LE method (red) together with the AERONET Level 2 Version 2 inversion (blue) both as a function of solar zenith angle (SZA). (b) Percentage difference (PFR-CIMEL) of $R_{\text {eff }}$ calculated from direct-sun data using the LE method (red) and the AERONET Level 2 Version 2 inversion (blue) both as a function of AOD.

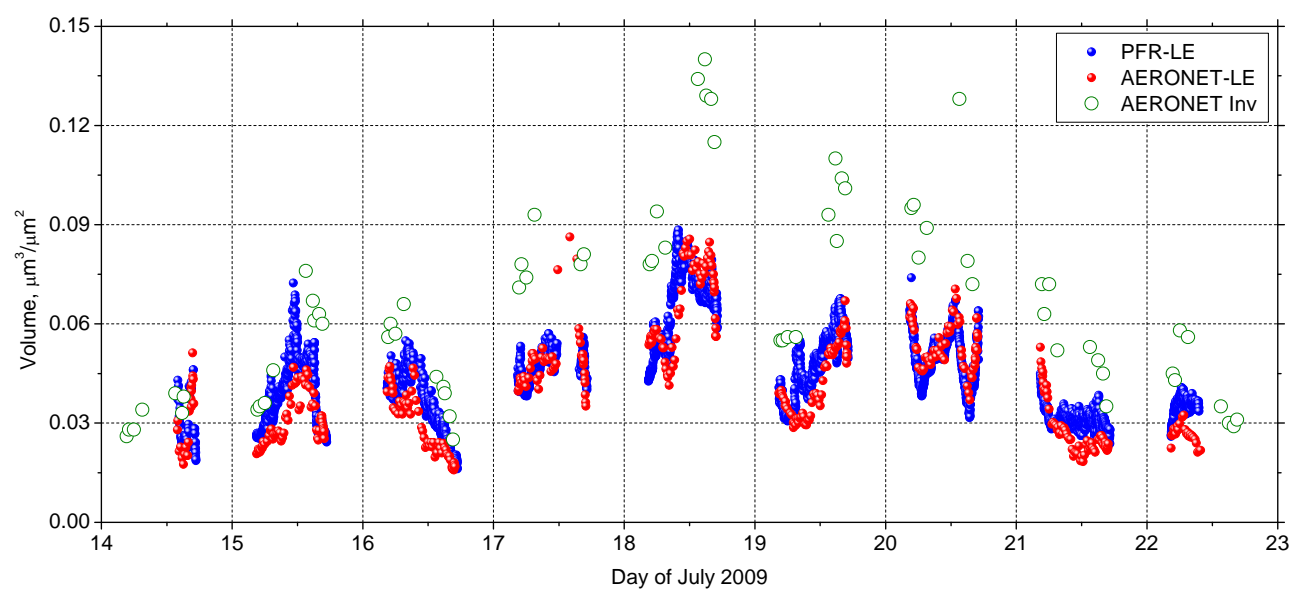

Figure 8. Time series of the volume concentration $V_{\mathrm{c}}$ during the measurement period calculated by the PFR-LE (blue), the AERONET-LE (red), and the AERONET inversion algorithm (green).

moderate to high AODs (>0.4). The two LE methods agree quite well $(5 \%)$ when direct-sun data are used and when the aerosol load is greater than 0.4. At lower aerosol loadings, the PFR-derived $V_{\mathrm{c}}$ appears to be higher by approximately $10-20 \%$. The situation is reversed with AERONET inversion data for which the difference with respect to PFR-LE tends to steadily increase (with LE retrieving showing lower $V_{\mathrm{c}}$ 's) with increasing AOD, and reaching a maximum difference of $0.04(-50 \%)$ for AOD $>0.4$.

When comparing volume concentrations retrieved from direct-sun measurements, we should remember that the PFR provides only four sources of input data, while the CIMEL instrument provides seven inputs, and so the retrieval from CIMEL data is expected to be more accurate. Furthermore, as will be shown in Sect 3.3, the retrieval is quite sensitive to noise in the input data, and a difference in the error distribution of data from the channels of both instruments may also cause the difference in retrieved parameters.

\subsection{Uncertainties in the retrieval}

One of the basic issues when a new inversion technique is considered is a realistic estimation of uncertainties related to the retrieval of particle parameters. As was shown by Veselovskii et al. (2012), in the absence of input errors, the uncertainties of the retrieval are due to the null space and the unknown value of the refractive index $m$. It should be mentioned that, while the AOD is not very sensitive to $m$ on the one hand and has the desired effect of decreasing corresponding errors, on the other hand this deprives one of the possibility of estimating the value of $m$ from measurements. Furthermore, the presence of random errors in the input data induces additional uncertainties in the retrieval. To estimate this, a numerical simulation was performed. Synthetic optical data corresponding to four measurement channels of the PFR were computed from a bimodal PSD of the form 

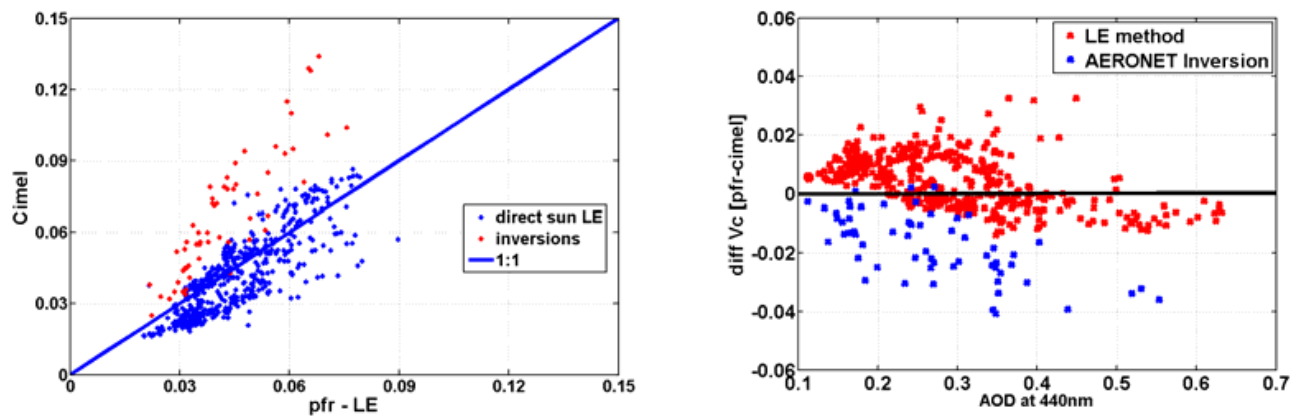

Figure 9. (a) Scatter plot of $V_{\mathrm{c}}$ from CIMEL using direct-sun data and the LE method (blue) and $V_{\mathrm{c}}$ from AERONET Level 2 Version 2 inversion (red) as a function of $V_{c}$ calculated from PFR-LE over the measurement period. (b) Difference (PFR-CIMEL) of $V_{c}$ calculated from direct-sun data using the LE method (red) and with the AERONET Level 2 Version 2 inversion (blue) both as a function of AOD.

Table 2. Parameters of two types of particle size distribution used in the numerical simulations.

\begin{tabular}{rrrrr}
\hline Type & $r_{\mathrm{f}}$ & $r_{\mathrm{c}}$ & $\ln \sigma$ & $N_{\mathrm{f}} / N_{\mathrm{c}}$ \\
\hline I & 0.1 & 1.0 & 0.4 & $10^{4}$ \\
II & 0.1 & 1.0 & 0.4 & $10^{2}$ \\
\hline
\end{tabular}

$\frac{\mathrm{d} n(r)}{\mathrm{d} \ln (r)}=\sum_{i=\mathrm{f,c}} \frac{N_{i}}{(2 \pi)^{1 / 2} \ln \sigma_{i}} \exp \left[-\frac{\left(\ln r-\ln r_{i}\right)^{2}}{2\left(\ln \sigma_{i}\right)^{2}}\right]$

with $N_{i}=N_{\mathrm{f}, \mathrm{c}}$ being the particle number density of the fine (f) and the coarse (c) modes. Each mode is represented by a lognormal distribution with modal radius $r_{\mathrm{f}, \mathrm{c}}$ and dispersion $\ln \sigma_{\mathrm{f}, \mathrm{c}}$. In our simulations, we used two types of PSD having the parameterization listed in Table 2. The fine and coarse modes have modal radii $r_{\mathrm{f}}=0.1 \mu \mathrm{m}$ and $r_{\mathrm{c}}=1 \mu \mathrm{m}$, respectively, with dispersion $\ln \sigma_{\mathrm{f}}=0.4$. The refractive index $m=1.45-i .005$ was assumed to be the same for both modes. The Type I distribution $\left(N_{\mathrm{f}} / N_{\mathrm{c}}=10^{4}\right)$ represents the situation where the fine mode is dominating the PSD, while the Type II distribution $\left(N_{\mathrm{f}} / N_{\mathrm{c}}=10^{2}\right)$ corresponds to a PSD where the coarse mode is prevalent.

The uncertainty of the AOD measurements is about 0.02 for both the PFR and the AERONET instruments; thus, for an AOD value of 0.2 , the relative error can be up to $10 \%$. In addition, the errors in long-wavelength channels can be higher than in short-wavelength channels since the corresponding AODs are also lower. In the somewhat idealized and simplified simulation presented here, we assumed that the uncertainties in all measurement channels are equivalent. To evaluate the effect of the input uncertainties on the retrieval, random errors in the range of $[0, \pm \varepsilon]$ were added to the PFR data, and from this "perturbed" optical data, bulk particle parameters were retrieved. To increase the sample, the procedure was repeated 1000 times as a bootstrap and to allow for more robust statistics. The results are presented in the form of cumulative probability distributions in Fig. 10.

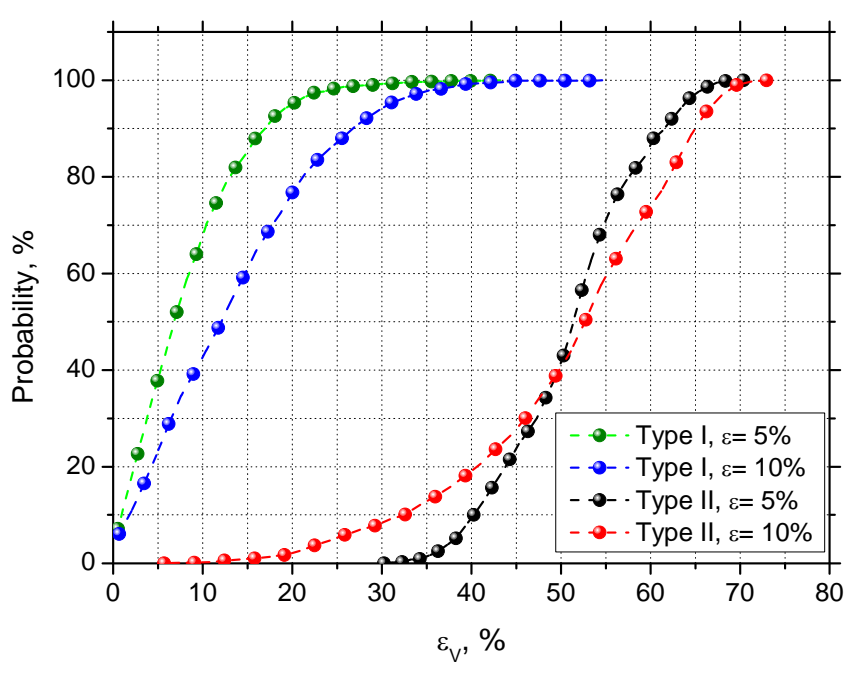

Figure 10. Cumulative probability of the uncertainty $\varepsilon_{\mathrm{V}}$ in the volume concentration retrieval from the PFR data set with input errors $\varepsilon=5 \%$ and $10 \%$ for Type I and Type II PSDs.

Simulations were performed for $\varepsilon=5$ and $0 \%$. For every value of $\varepsilon_{\mathrm{V}}$ the plot gives the probability that the retrieval uncertainty is below this quoted value. For example, for the Type I distribution, in $90 \%$ of the cases the uncertainty of the $V_{\mathrm{c}}$ estimation is below $\varepsilon_{\mathrm{v}} \approx 15$ and $25 \%$ for input errors of magnitude $\varepsilon=5$ and $10 \%$, respectively. Similar probability curves were calculated for $R_{\text {eff }}$. The results of the simulation for PFR data are summarized in Table 3 and show $\varepsilon_{R_{\text {eff }}}$ and $\varepsilon_{\mathrm{v}}$ at the $90 \%$ level of significance as well as the uncertainty obtained in the absence of errors on the input data. In the absence of input errors $(\varepsilon=0)$ the uncertainties are below $10 \%$ and $20 \%$ for $V_{\mathrm{c}}$ and $R_{\text {eff }}$ when the distribution has a prevailing fine mode (Type I). However in the presence of a strong coarse mode (Type II), these errors increase to 50 and $30 \%$, respectively. While the presence of random errors in the input data increases the uncertainty further, we are still able to estimate $R_{\text {eff }}$ with an uncertainty $<60 \%$ and $V_{\mathrm{c}}$ with an uncertainty $<65 \%$ (for aerosol loads when AOD $>0.2$ ). 
Table 3. Uncertainties of effective radius $\varepsilon_{R_{\text {eff }}}$ and volume concentration $\varepsilon_{\mathrm{V}}$ retrieval for Type I and II PSDs.

\begin{tabular}{lrrrrr}
\hline \multirow{2}{*}{ Input errors, $\%$} & \multicolumn{2}{c}{$\varepsilon_{R_{\text {eff }}, \%}$} & & \multicolumn{2}{c}{$\varepsilon_{\mathrm{v}}, \%$} \\
\cline { 2 - 3 } \cline { 5 - 6 } & Type I & Type II & & Type I & Type II \\
\hline 0 & 20 & 30 & & 10 & 50 \\
5 & 40 & 50 & & 15 & 60 \\
10 & 50 & 60 & & 25 & 65 \\
\hline
\end{tabular}

As mentioned earlier, the uncertainties in the inversion obtained for $\varepsilon=0$ include the errors arising from both the existence of the null space and also from an incorrect choice of the refractive index. To estimate the influence of this second factor, we performed retrievals assuming $m_{\mathrm{R}}=1.35$ and 1.55 (while the model value was $m_{\mathrm{R}}=1.45$ ). For Type II aerosol, the variance of retrieved parameters was below $10 \%$. Small particles (Type I) are more sensitive to the choice of $m_{\mathrm{R}}$, and corresponding variances are up to $\sim 30 \%$ for $R_{\text {eff }}$ and up to $15 \%$ for $V_{\mathrm{c}}$. However, the insensitivity of the data to the real part of the refractive index allowed us to make an estimation of $m_{\mathrm{R}}$ from the measurements, and the final retrieval uncertainty was found to be below $20 \%$ for $R_{\text {eff }}$ and below $10 \%$ for the $V_{\mathrm{c}}$ as shown in Table 3. The influence of the imaginary part was found to be even less significant, and a choice of $m_{\mathrm{I}}=0.01$ instead 0.005 did not increase errors of retrieval by more than $5 \%$.

In trying to distinguish Type I from Type II cases during instrument operation, an analysis of long-term statistics of AERONET measurements led to the conclusion that for $\mathrm{AE}(440-870)>1.5$ more than $70 \%$ of AOD at $500 \mathrm{~nm}$ is attributable to the fine mode, i.e. Type I. Similarly, for $\mathrm{AE}<0.5$ the coarse mode contributes above $70 \%$ to the AOD, suggesting that such conditions can be treated as Type II. For $0.5<\mathrm{AE}<1.5$ the errors are intermediate.

The values presented in Table 3 represent the absolute errors of retrieval (relative changes of parameters can obtained with lower uncertainty). For example, if the particle effective radius and refractive index do not vary much, the uncertainties due to the null space and the choice of inversion interval are also quite stable. In this case, a relative change in the particle volume can be evaluated with significantly lower uncertainty than that given in Table 3 .

The numerical simulations in our paper were performed only for two extreme cases where either fine mode or the coarse mode dominates PSDs - so as to illustrate the main trend that there is an increase in the retrieval uncertainty when the coarse mode dominates. For more realistic scenarios, a wider range of particle mode parameters and refractive indices should be considered. While we are in the process of performing more detailed studies, here we would like draw attention to the following considerations:
1. Because the problem is underdetermined, uncertainties can be decreased by narrowing the "search space" via the inversion interval. In particular, the spectral dependence of the Angstrom parameter allows for a decomposition of the contributions of the fine and coarse modes using the AOD (O'Neill et al., 2003), and this information can be used to constrain $r_{\min }$ and $r_{\max }$ ranges used in the retrieval. Inclusion of the spectral dependence of the Ångstrom parameter in analyses should improve the retrieval and provide a basis for characterization of retrieval uncertainties.

2. Since AERONET retrievals can be considered to be "true", accumulation of sufficient statistics for different types of aerosol may allow for the introduction of a correction to the LE retrieval to decrease its uncertainty (especially for larger coarse-mode particles).

\section{Conclusions}

In this study we have used synchronized sun-photometric measurements from two different instruments that are used by the AERONET (CIMEL sun photometer) and GAW (PFR sun photometer) aerosol networks. Comparing AOD retrievals, we found small absolute differences of the order 0.01 and 0.02 , similar to the AOD uncertainty of 0.015 quoted for both types of instrument. Regression analyses on coincident AODs resulted in Pearson product-moment correlation coefficients $>0.99$ and regression line slopes from 0.99 to 1.04 at all wavelengths - indicating a very strong agreement in the AOD retrievals.

During the measurement period, a substantial increase in fine-mode aerosol of radius $r \approx 0.15 \mu \mathrm{m}$ on 18 and 20 July was observed. In this context, both PFR- and CIMEL-derived inversions agreed fairly well with regard to general features in plots of $R_{\text {eff }}$ and $V_{\mathrm{c}}$. For low aerosol loads (AOD $<0.2$ ), measurements of $R_{\text {eff }}$ by the PFR are $-20 \%$ to $+30 \%$ different from CIMEL values for both direct-sun data and inversion data. At higher loads (AOD > 0.4), measurements of $R_{\text {eff }}$ by the PFR are consistently $20 \%$ lower than CIMEL for both direct-sun and inversion data.

Concentrations at low aerosol loads from the PFR are up to $80 \%$ higher than the CIMEL for direct-sun data, but inversion data suggest that $V_{\mathrm{c}}$ retrievals from the PFR are up to $20 \%$ lower than those obtained from the CIMEL. Higher aerosol loads were found to not rectify this situation. For AOD $>0.4$, the percentage difference in $V_{c}$ from the PFR and CIMEL is systematically around $5 \%$.

Application of the LE method to both CIMEL and PFR AOD measurements gave reasonable agreement in the retrievals. However, this study shows that implementation of such results to direct-sun instruments requires the use of highly accurate AOD data since small AOD differences can have a sizeable impact on the calculated values of $R_{\text {eff }}$ and $V_{\mathrm{c}}$. The calculation of these bulk parameters by the LE 
method show an underestimation compared with those obtained from AERONET inversions, with the highest differences being observed for $\mathrm{AOD}<0.2$ and for $\mathrm{SZA}>70^{\circ}$. We note that the LE technique is applied to pure spectral particle extinction data (no sky radiance information via the phase function is available), in contrast to the AERONET inversion method, and utilizes only four instead of seven wavelengths.

As such, AERONET inversion retrieval products used for comparison here represent the current quality standard. Despite observed differences, the use of the LE method with direct-sun sun-photometer data is found to offer a number of advantages, including

a. a unique opportunity to spatially expand the global data set of bulk aerosol properties $\left(R_{\text {eff }}\right.$ and $\left.V_{\mathrm{c}}\right)$ by using GAW-PFR network data in conjunction with other direct-sun (AOD-measuring) instruments,

b. a unique opportunity to collect high-temporalresolution time series data of bulk particle parameters by using AERONET or other instruments' AOD measurements that can be provided (or already exist) in various aerosol databases with a frequency of 1-15 min,

c. a new contribution to satellite validation studies that require dense ground-based measurements. For example, clean continental aerosol types are not well represented in the AERONET data set, and the GAW-PFR network can add to that. In our opinion, the significance of the application of the LE method to PFR is high and this study is a first step in this direction. Moreover, we believe that it is critical that the products of other sunphotometric networks be expanded so as to contribute to satellite validation activities with a new and independent source of information that can complement that provided by AERONET.

Acknowledgements. M. Taylor was supported by a Marie-CurieIEF-funded project "AEROMAP: Global mapping of aerosol properties using neural network inversions of ground and satellite based data", CN: 300515. S. Kazadzis's work is supported by the project FP7-PEOPLE-2009-RG Marie Curie European Reintegration Grant, PERG-GA-2009-256391. The authors would like to thank the anonymous reviewers for their valuable comments and suggestions to improve the quality of the paper.

Edited by: M. Wendisch

\section{References}

Bohren, C. F. and Huffman, D. R.: Absorption and Scattering of Light by Small Particles, John Wiley, Hoboken, NJ, 1983.

De Graaf, M., Donovan, D., and Apituley, A.: Feasibility study of integral property retrieval for tropospheric aerosol from Raman lidar data using principal component analysis, Appl. Opt., 52, 2173-2186, 2013.

Donovan, D. and Carswell, A.: Principal component analysis applied to multiwavelength lidar aerosol backscatter and extinction measurements, Appl. Opt., 36, 9406-9424, 1997.

Dubovik, O. and King, M. D.: A flexible inversion algorithm for retrieval of aerosol optical properties from Sun and sky radiance measurements, J. Geophys. Res., 105, 20673-20696, 2000.

Dubovik, O., Smirnov, A., Holben, B. N., King, M. D., Kaufman, Y. J., Eck, T. F., and Slutsker, I.: Accuracy assessments of aerosol optical properties retrieved from Aerosol Robotic Network (AERONET) Sun and sky radiance measurements, J. Geophys. Res., 105, 9791-9806, doi:10.1029/2000JD900040, 2000.

Dubovik, O., Holben, B., Eck, T. F., Smirnov, A., Kaufman, Y. J., King, M. D., Tanré, D., and Slutsker, I.: Variability of absorption and optical properties of key aerosol types observed in worldwide locations, J. Atmos. Sci., 59, 590-608, 2002.

Dubovik, O., Sinyuk, A., Lapyonok, T., Holben, B. N., Mishchenko, M., Yang, P., Eck, T. F., Volten, H., Muñoz, O., Veihelmann, B., van der Zande, W. J., Leon, J.-F., Sorokin, M., and Slutsker, I.: Application of spheroid models to account for aerosol particle nonsphericity in remote sensing of desert dust, J. Geophys. Res., 111, D11208, doi:10.1029/2005JD006619, 2006.

Fotiadi, A., Hatzianastassiou, N., Drakakis, E., Matsoukas, C., Pavlakis, K. G., Hatzidimitriou, D., Gerasopoulos, E., Mihalopoulos, N., and Vardavas, I.: Aerosol physical and optical properties in the Eastern Mediterranean Basin, Crete, from Aerosol Robotic Network data, Atmos. Chem. Phys., 6, 53995413, doi:10.5194/acp-6-5399-2006, 2006.

Gerasopoulos, E., Koulouri, E., Kalivitis, N., Kouvarakis, G., Saarikoski, S., Mäkelä, T., Hillamo, R., and Mihalopoulos, N.: Size-segregated mass distributions of aerosols over Eastern Mediterranean: seasonal variability and comparison with AERONET columnar size-distributions, Atmos. Chem. Phys., 7, 2551-2561, doi:10.5194/acp-7-2551-2007, 2007.

Gerasopoulos, E., Amiridis, V., Kazadzis, S., Kokkalis, P., Eleftheratos, K., Andreae, M. O., Andreae, T. W., El-Askary, H., and Zerefos, C. S.: Three-year ground based measurements of aerosol optical depth over the Eastern Mediterranean: the urban environment of Athens, Atmos. Chem. Phys., 11, 2145-2159, doi:10.5194/acp-11-2145-2011, 2011.

Hansen, J., Nazarenko, L., Ruedy, R., Sato, M., Willis, J., Del Genio, A., Koch, D., Lacis, A., Lo, K., Menon, S., Novakov, T., Perlwitz, J., Russell, G., Schmidt, G. A., and Tausnev, N.: Earth's energy imbalance: Confirmation and implications, Science, 308, 1431-1435, doi:10.1126/science.1110252, 2005.

Hansen, J., Sato, M., Lacis, A., and Ruedy, R.: The missing climate forcing, Phil. Trans. Royal Soc. London B, 352, 231-240, 1997.

Haywood, J. M., Johnson, B. T., Osborne, S. R., Baran, A. J., Brooks, M., Milton, S. F., Mulcahy, J., Walters, D., Allan, R. P., Klaver, A., Formenti, P., Brindley, H. E., Christopher, S., AND Gupta, P.: Motivation, rationale and key results from the GERBILS Saharan dust measurement campaign, Q. J. R. Meteorol. Soc., 137, 1106-1116, 2011. 
Holben, B. N., Eck, T. F., Slutsker, I., Tanre, D., Buis, J. P., Setzer, A., Vermote, E., Reagan, J. A., Kaufman, Y., Nakajima, T., Lavenu, F., Jankowiak, I., and Smirnov, A.: AERONET - a federated instrument network and data archive for aerosol characterization, Remote Sens. Environ., 66, 1-16, 1998.

IPCC: Climate Change 2007 - The Physical Science Basis: Contribution of the Working Group I to the Fourth Assessment Report of the IPCC, Cambridge University Press, New York, NY, USA, 2007.

King, M. D., Byrne, D. M., Herman, B. M., and Reagan, J. A.: Aerosol size distributions obtained by inversion of spectral optical depth measurements, J. Atmos. Sci., 35, 2153-2167, 1978.

Lopatin, A., Dubovik, O., Chaikovsky, A., Goloub, P., Lapyonok, T., Tanré, D., and Litvinov, P.: Enhancement of aerosol characterization using synergy of lidar and sun-photometer coincident observations: the GARRLiC algorithm, Atmos. Meas. Tech., 6, 2065-2088, doi:10.5194/amt-6-2065-2013, 2013.

McArthur, L. J. B., Halliwell, D. H., Niebergall, O. J., O’Neill, N. T., Slusser, J. R., and Wehrli, C.: Field comparison of network sunphotometers. J. Geophys. Res., 108, 4596, doi:10.1029/2002JD002964, 2003.

Mishchenko, M. I., Travis, L. D., and Lacis, A. A.: Multiple Scattering of Light by Particles, Radiative Transfer and Coherent Backscattering, Cambridge University Press, 2006.

Mishchenko, M. I., Geogdzhayev, I. V., Rossow, W. B., Cairns, B., Carlson, B. E., Lacis, A. A., Liu, L., and Travis, L. D.: Long-term satellite record reveals likely recent aerosol trend, Science, 315, 1543-1543, 2007.

Müller, D., Wandinger, U., and Ansmann, A.: Microphysical particle parameters from extinction and backscatter lidar data by inversion with regularization: theory, Appl. Opt., 38, 2346-2357, 1999.

Müller, D., Weinzierl, B., Petzold, A., Kandler, K., Ansmann, A., Müller, T., Tesche, M., Freudenthaler, V., Esselborn, M., Heese, B., Althausen, D., Schladitz, A., Otto, S., and Knippertz, P.: Mineral dust observed with AERONET Sun photometer, Raman lidar, and in situ instruments during SAMUM 2006: Shapeindependent particle properties, J. Geophys. Res., 115, D07202, doi:10.1029/2009JD012520, 2010.

O’Neill, N. T., Eck, T. F., Smirnov, A., Holben, B., and Thulasiraman, S.: Spectral discrimination of coarse and fine mode optical depth, J. Geophys. Res., 108, 4559, doi:10.1029/2002JD002975, 2003.
Smirnov, A., Holben, B. N., Eck, T. F., Dubovik, O., and Slutsker, I.: Cloud screening and quality control algorithms for Aeronet database, Remote Sens. Environ., 73, 337-349, 2000.

Thomason, L. W. and Osborn, M. T.: Lidar conservation parameters derived from SAGE II extinction measurements, Geophys. Res. Lett., 19, 1655-1658, 1992.

Toledano, C., Wiegner, M., Gross, S., Freudenthaler, V., Gasteiger, J., Mueller, D., Mueller, T., Schladitz, A., Weinzierl, B., Torres, B., and O'Neill, N. T.: Optical properties of aerosol mixtures derived from sun sky radiometry during SAMUM 2, Tellus Ser. B, 63, 635-648, doi:10.1111/j.1600-0889.2011.00573.x, 2011.

Twomey, S.: Introduction to the Mathematics of Inversion in Remote Sensing and Linear Measurements, Elsevier, New York, 1977.

Wehrli, C.: GAW-PFR: A network of Aerosol Optical Depth observations with Precision Filter Radiometers, in: WMO/GAW Experts workshop on a global surface based network for long term observations of column aerosol optical properties, GAW Report No. 162, WMO TD No. 1287, 2005.

WMO: WMO/GAW Experts workshop on a global surface-based network for long term observations of column aerosol optical properties, Davos 2004, edited by: Baltensperger, U., Barrie, L., and Wehrli, C., GAW No. 162, WMO/TD-No. 1287, available at: ftp://ftp.wmo.int/Documents/PublicWeb/arep/gaw/ gaw162.pdf, 2005.

Veselovskii, I., Kolgotin, A., Griaznov, V., Müller, D., Wandinger, U., and Whiteman, D. N.: Inversion with regularization for the retrieval of tropospheric aerosol parameters from multiwavelength lidar sounding, Appl. Opt., 41, 3685-3699, 2002.

Veselovskii, I., Dubovik, O., Kolgotin, A., Korenskiy, M., Whiteman, D. N., Allakhverdiev, K., and Huseyinoglu, F.: Linear estimation of particle bulk parameters from multi-wavelength lidar measurements, Atmos. Meas. Tech., 5, 1135-1145, doi:10.5194/amt-5-1135-2012, 2012.

Veselovskii, I., Whiteman, D. N., Korenskiy, M., Kolgotin, A., Dubovik, O., Perez-Ramirez, D., and Suvorina, A.: Retrieval of spatio-temporal distributions of particle parameters from multiwavelength lidar measurements using the linear estimation technique and comparison with AERONET, Atmos. Meas. Tech., 6, 2671-2682, doi:10.5194/amt-6-2671-2013, 2013. 